\title{
Highly Enhanced Heavy Metal Adsorption Performance of Iron Oxide (Fe-Oxide) upon Incorporation of Aluminum
}

\author{
Hye-Jin Hong ${ }^{1}$, Ji-Won Yang ${ }^{2}$, Jung-Seok Yang ${ }^{3}$ and Hyeon Su Jeong 4,* \\ ${ }^{1}$ Korea Institute of Geoscience and Mineral Resources (KIGAM), Gwahak-ro 124, Yuseong-gu, Daejeon, 34132, Republic of Korea \\ ${ }^{2}$ Department of Chemical and Biomolecular Engineering, KAIST, 291, Daehak-re, Yuseong-gu, Daejeon 34141, Republic of Korea \\ ${ }^{3}$ KIST Gangneung Institute, 679, Saimdang-ro, Gangneung-si, Gangwon-do 25451, Republic of Korea \\ ${ }^{4}$ Applied Quantum Composite Research Center, Korea Institute of Science and technology (KIST), \\ Eunha-ri San 101, Bongdong-eup, Wanju-gun, Jeollabuk-do 565-905, Republic of Korea
}

Iron oxide (Fe-oxide) has been widely used in the adsorption of heavy metals from aqueous solution. In this study, we improve the heavy metal adsorption capacity of Fe-oxide by synthesizing its binary oxide with aluminum (Al). In addition, we discuss the effect of characteristic changes caused by $\mathrm{Al}$ incorporation on the removal of arsenate (As(V)) and selenate (Se(VI)). Binary oxides with six different Fe:Al ratios (10:0, 9:1, 7:3, 5:5, 3:7 and 1:9) are synthesized by the sol-gel method, followed by a sintering process. The SEM-EDS result reveals that Fe and $\mathrm{Al}$ are homogeneously distributed in the oxides. It is found that the incorporation of $\mathrm{Al}$ into Fe-oxide not only provides a high specific surface area $\left(90 \sim 200 \mathrm{~m}^{2} / \mathrm{g}, 10\right.$ times larger than pure Fe-oxide) but also inhibits the phase transition from $\alpha$-FeOOH to $\alpha$-Fe $\mathrm{O}_{3}$. The combination of the expanded surface area and the $\alpha-\mathrm{FeOOH}$ phase, which has a plentiful supply of hydroxyl groups, plays a crucial role in improving As(V) and $\mathrm{Se}(\mathrm{VI})$ adsorption. Among various Fe:Al ratio binary oxides, the highest uptake is achieved with 5:5 Fe:Al oxide sintered at $100^{\circ} \mathrm{C}$. [doi:10.2320/matertrans.M2016277]

(Received August 2, 2016; Accepted October 18, 2016; Published November 18, 2016)

Keywords: $\quad$ iron oxide, aluminum, mixed oxide, arsenate, selenate, removal

\section{Introduction}

Iron oxides (Fe-oxide) in their various forms exhibit interesting properties such as catalytic activity, large surface area, positive surface charge and various functional groups ${ }^{1)}$. Because of these advantageous properties, Fe-oxide is widely applied for the remediation of contaminated environments. Among various applications, heavy metal removal from waste aqueous solution is under active investigation ${ }^{2-6)}$. Y.-H. Huang et al. investigated copper ( $\mathrm{Cu}(\mathrm{II}))$ removal by $\mathrm{Fe}-\mathrm{Ox}-$ $\mathrm{ide}^{7)}$. M. Rovira et al. removed selenate (Se(VI)) using natural Fe-oxides and discovered the adsorption mechanisms ${ }^{8)}$. Zhong synthesized self-assembled 3D flowerlike Fe-oxide for the adsorption of arsenate $(\mathrm{As}(\mathrm{V}))$ and hexa-valent chromium $(\mathrm{Cr}(\mathrm{VI}))^{9)}$.

Recently, to improve the heavy metal adsorption capacity of Fe-oxide, several modification methods have been investigated. The incorporation of foreign metal into Fe-oxide is one modification method to improve its adsorption capability ${ }^{10)}$. K. Gupta investigated the incorporation of Ti into Fe-oxide and applied the combination to $\mathrm{As}(\mathrm{V})$ and arsenite (As(III)) removal $^{11)}$. Fe-Mn binary oxide is also reported to exhibit good performance for As(III) adsorption accompanied with oxidation property of Mn-oxide ${ }^{12,13)}$.

In this study, we aimed to enhance the heavy metal adsorption capacity of Fe-oxide by incorporating Al. Amorphous Al-oxide is known to exhibit an extremely large surface area along with good thermal and chemical stability. These advantages of Al-oxide may improve the heavy metal adsorption characteristics of Fe-oxide. There have been several attempts to synthesize Fe-Al binary oxide for heavy metal removal, and some have enhanced the heavy metal sorption capacity of $\mathrm{Fe}$-oxide after incorporation of $\mathrm{Al}^{14,15)}$. However, the reason

*Corresponding author, E-mail: jeonghs98@kist.re.kr the incorporation of $\mathrm{Al}$ into Fe-oxide results in good heavy metal sorption capacity is not yet clear.

Herein, six Fe-Al binary oxides with different Fe:Al ratios (10:0, 1:9, 7:3, 5:5, 3:7 and 1:9) are synthesized by the sol-gel method, followed by a sintering process. Characteristic changes such as morphology, surface area and crystallinity upon incorporating $\mathrm{Al}$ are investigated, and the effects of those changes on the heavy metal adsorption capacity of Fe-oxide are discussed. Finally, As(V), and Se(VI) adsorption on Fe-Al binary oxide are performed to evaluate the heavy metal adsorption capacity of $\mathrm{Fe}-\mathrm{Al}$ binary oxide based on the Fe:Al ratio.

\section{Experimental Procedure}

\subsection{Synthesis of Fe-Al binary oxide}

Fe-Al binary oxide was synthesized by the sol-gel method. A solution was prepared by mixing $1 \mathrm{~mol} / \mathrm{L}$ each of iron chloride $\left(\mathrm{FeCl}_{3}\right.$, Aldrich) and aluminum chloride $\left(\mathrm{AlCl}_{3}, \mathrm{Al}-\right.$ drich), and then $2 \mathrm{~mol} / \mathrm{L}$ of $\mathrm{NaOH}$ (Junsei) was added to this solution under vigorous stirring at room temperature. The $\mathrm{pH}$ of the suspension at the end of the reaction was 5.6-6.2. The precipitates were aged in the mother solution for $12 \mathrm{~h}$, and they settled at the bottom of the beaker. After carefully removing the supernatant, the precipitate was washed with distilled water to remove by-products. The resulting $\mathrm{Fe}-\mathrm{Al}$ hydrogel was dried and ground, then sintered at 100, 300, and $500^{\circ} \mathrm{C}$ for $5 \mathrm{~h}$ without supplying gas. The $\mathrm{Fe}: \mathrm{Al}$ ratios tested were 10:0, 9:1, 7:3, 5:5, 3:7 and 1:9. The Fe:Al ratio was defined as the molar ratio of $\mathrm{AlCl}_{3}$ and $\mathrm{FeCl}_{3}$.

\subsection{Heavy metal adsorption experiment by Fe-Al binary oxide}

Synthesized $\mathrm{Fe}-\mathrm{Al}$ binary oxides with various $\mathrm{Fe}$ :Al molar ratios, sintered at different temperatures, were evaluated for 
their ability to remove heavy metals. Arsenate(As(V)) and selenate(Se(VI)) were used as model pollutants. We used $0.5 \mathrm{~g} / \mathrm{L}$ of $\mathrm{Fe}-\mathrm{Al}$ binary oxide with an initial pollutant concentration of $100 \mathrm{mg} / \mathrm{L}$ and solution $\mathrm{pH}$ was 5.6. The adsorption experiments were performed in a $20 \mathrm{ml}$ glass vial. The oxides were mixed with the pollutant solution for $24 \mathrm{~h}$ at room temperature. Then, the used Fe-Al binary oxides were left to settle at the bottom of the vial, and the final heavy metal concentration of the supernatant was analyzed. Sodium arsenate $\left(\mathrm{NaHAsO}_{4} \cdot 7 \mathrm{H}_{2} \mathrm{O}\right)$ and sodium selenate $\left(\mathrm{Na}_{2} \mathrm{SeO}_{4}\right)$ were used as sources of heavy metal. All chemicals were purchased from Sigma-Aldrich.

\subsection{Characteristic analysis}

Scanning electron microscopy (SEM, FEI Helios NanoLab 650, USA) = equipped energy-dispersive X-ray spectroscopy (EDS) was used to observe the morphology of the Fe-Al binary oxides and the distribution of each element. EDS mapping with $10 \mathrm{kV}$ electrons was performed on the surface of the binary mixture. The surface area of the synthesized $\mathrm{Fe}-\mathrm{Al}$ binary oxide was analyzed by $\mathrm{N}_{2}$ adsorption-desorption isotherms measured by BET surface analyzer (Tristar $3000 \mathrm{Mi}-$ crometrics, USA).

X-ray diffraction (XRD, D/Max RB Rigaku, Japan) was used to analyze the crystallinity of the synthesized Fe-Al binary oxide. The XRD patterns were analyzed using the X-ray analysis software MDI/JADE.

\subsection{Analytical methods}

The concentrations of $\mathrm{As}(\mathrm{V})$ and $\mathrm{Se}(\mathrm{VI})$ was measured using an inductively coupled plasma-optical emission spectrophotometer (ICP-OES, 730-WA, Varian Inc., USA)

The adsorbed amounts of $\mathrm{As}(\mathrm{V})$ and $\mathrm{Se}(\mathrm{VI})$ were calculated as follows:

$$
q(m g / g)=\frac{\left(C_{i}-C_{f}\right) \times V}{m}
$$

where $q$ is the amount of $\mathrm{As}(\mathrm{V})$ or $\mathrm{Se}(\mathrm{VI})$ adsorbed onto $\mathrm{Fe}$ Al binary oxides $(\mathrm{mg} / \mathrm{g})$, and $C_{i}$ and $C_{f}$ are the mean initial and final concentrations of the pollutant $(\mathrm{mg} / \mathrm{L})$, respectively. $V$ is the volume of the solution (L), and $m$ is the amount of
Fe-Al binary oxide $(\mathrm{g})$.

\section{Results and Discussions}

\subsection{Elemental distribution of Fe-Al binary oxides}

Figure 1(a) shows a representative SEM image of Fe-Al binary oxide in a molar ratio of 5:5 synthesized by the sol-gel method. It reveals that the $\mathrm{Fe}-\mathrm{Al}$ binary oxide has an irregular shape and an average size approximately $10 \mu \mathrm{m}$. To analyze the elemental distribution in Fe-Al binary oxide according to $\mathrm{Fe}$ :Al ratio, EDS analysis was performed with Fe-Al binary oxides sintered at $100^{\circ} \mathrm{C}$. In Fig. 1(b), the overlapped mapping image of $\mathrm{Fe}$ and $\mathrm{Al}$, color-coded, are shown according to the $\mathrm{Fe}$ :Al ratio. Orange and yellow indicate $\mathrm{Fe}$ and $\mathrm{Al}$, respectively. EDS elemental mapping shows a uniform distribution of each color regardless of $\mathrm{Fe}: \mathrm{Al}$ ratios, indicating that $\mathrm{Fe}$ and $\mathrm{Al}$ are homogenously mixed over the area with no aggregation of each element. It should be noted that the color of the maps changes from dark red to brown and finally to light green, indicating changes in the concentrations of each element. This sequential change of color in the EDS maps corresponds to increasing $\mathrm{Al}$ content in the binary oxide. Figure 1(c) shows the quantitative data of Fe and Al in the EDS inspection field in units of atomic percent and confirms that the atomic percentage of each element is almost consistent with the as-synthesized molar ratio of $\mathrm{Fe}$ and $\mathrm{Al}$. For example, a Fe-Al binary oxide in a molar ratio of 5:5 shows an atomic composition of $55 \% \mathrm{Fe}$ and $45 \% \mathrm{Al}$.

\subsection{Morphology of Fe-Al binary oxides}

The morphology and surface characteristics of synthesized Fe-Al binary oxide were analyzed by SEM. Figure 2 shows SEM images of the synthesized Fe-Al binary oxides with various Fe:Al ratios and sintered at different temperatures. The morphology of pure Fe-oxide (Fe:Al ratio = 10:0) was significantly affected by the sintering temperature. At a $100^{\circ} \mathrm{C}$ sintering temperature, Fe-oxide showed a smooth surface, but calcination above $300^{\circ} \mathrm{C}$ caused deformation on the surface (Fig. 2 (a), (b) and (c)). At $300^{\circ} \mathrm{C}$, rod-shaped bumps are observed on the surface of the pure Fe-oxide. The surface transformed to ball-like bumps with a diameter of approximately

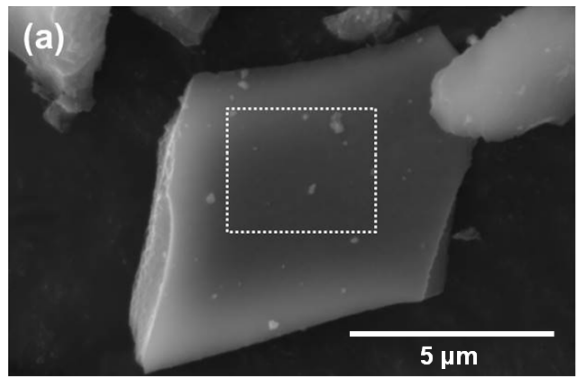

(b)
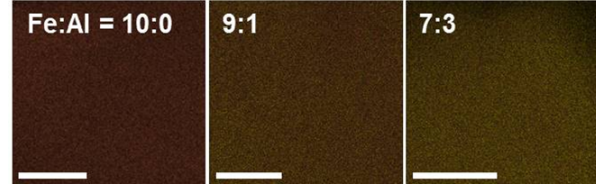

(c)
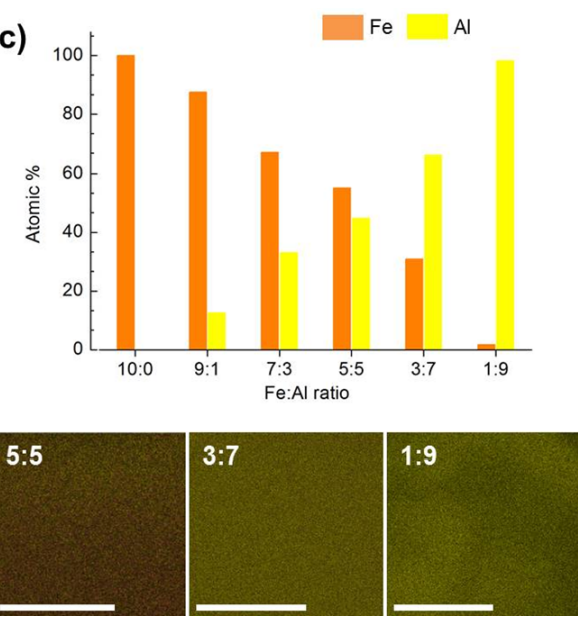

Fig. 1 SEM image of Fe-Al binary oxide with Fe:Al ratio 5:5 (a), SEM-EDS elemental mapping images according to Fe:Al ratio (sintered at $100^{\circ} \mathrm{C}$ ). All scale bar indicates $2 \mu \mathrm{m}$ (b), quantitative atomic percent from EDS area (c) according to Fe:Al ratio. 

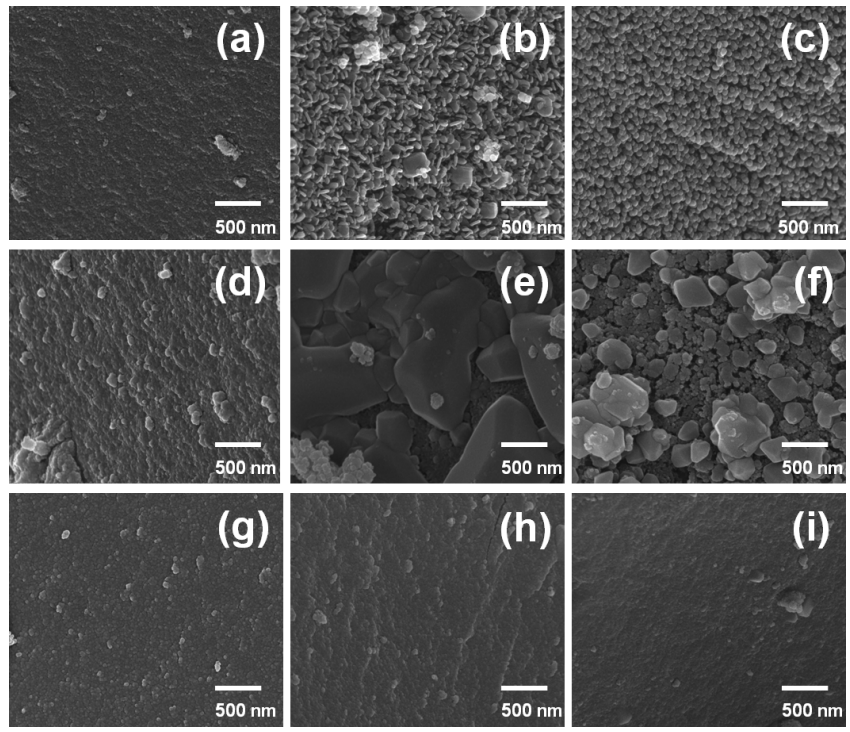

Fig. 2 SEM image of Fe-Al bindery oxide according to Fe:Al ratio and sintering temperature [Pure iron oxide (Fe:Al ratio 10:0) sintered at $100^{\circ} \mathrm{C}$ (a), $300^{\circ} \mathrm{C} \mathrm{(b),} 500^{\circ} \mathrm{C}$ (c), Fe:Al ratio $=9: 1$ sintered at $100^{\circ} \mathrm{C}(\mathrm{d}), 300^{\circ} \mathrm{C}$ (e), $500^{\circ} \mathrm{C}$ (f), $\mathrm{Fe}: \mathrm{Al}$ ratio $=7: 3$ sintered at $100^{\circ} \mathrm{C}(\mathrm{g}), 300^{\circ} \mathrm{C}(\mathrm{h}), 500^{\circ} \mathrm{C}$ (i)].

$50 \mathrm{~nm}$ when the Fe-oxide was sintered at $500^{\circ} \mathrm{C}$. The shape and distribution of bumps remained regular with increasing sintering temperature. This morphology change is attributed to the coarsening of the Fe-oxide surface ${ }^{16)}$. Increasing sintering temperature resulted in the coarsening of Fe-oxide, and the smooth surface converted to a regularly distributed bump-covered morphology.

The incorporation of $\mathrm{Al}$ into $\mathrm{Fe}$-oxide shows different surface characteristics from $\mathrm{Fe}$-oxide alone when sintered at the same temperature. A mixture of $10 \% \mathrm{Al}$ in Fe-oxide (Fe:Al ratio of 9:1) exhibits a similar coarsening behavior of Fe-oxide followed by the appearance of small bumps on the surface when the sintering temperature was increased to $300^{\circ} \mathrm{C}$ and $500^{\circ} \mathrm{C}$. However, the bumps are large and irregular compared with the ones in pure Fe-oxide, indicating that the incorporation of $\mathrm{Al}$ interferes with the coarsening of Fe-oxide and the resulting surface area reduction at high temperature. This phenomenon is more obvious with $\mathrm{Al}$ contents higher than $30 \%$. With Fe:Al ratios of 7:3, 5:5, 3:7 and 1:9, the surface morphology was not affected by the sintering temperature, and a smooth surface was observed at all tested temperatures.

\subsection{BET surface area of Fe-Al oxides}

Figure 3 shows the BET surface area of the prepared $\mathrm{Fe}-\mathrm{Al}$ binary oxides according to $\mathrm{Fe}: \mathrm{Al}$ ratio and sintering temperature. Pure Al-oxide (Fe:Al ratio of 0:10) shows the largest BET surface area regardless of the sintering temperature. Surface areas of 218,206 , and $209 \mathrm{~m}^{2}$ were obtained for $1 \mathrm{~g}$ of synthesized Al-oxide sintered at 100,300 , and $500^{\circ} \mathrm{C}$, respectively. The nearly constant value of the surface area indicates that $\mathrm{Al}$-oxide is not affected by sintering temperature. On the other hand, pure Fe-oxide (Fe:Al ratio of 10:0) shows a very small surface area, which is rapidly decreased by increasing the sintering temperature from 100 to $500^{\circ} \mathrm{C}$ due to coarsening. Only a $15.1 \mathrm{~m}^{2} / \mathrm{g}$ surface area is obtained for $500^{\circ} \mathrm{C}$ sintered pure Fe-oxide.

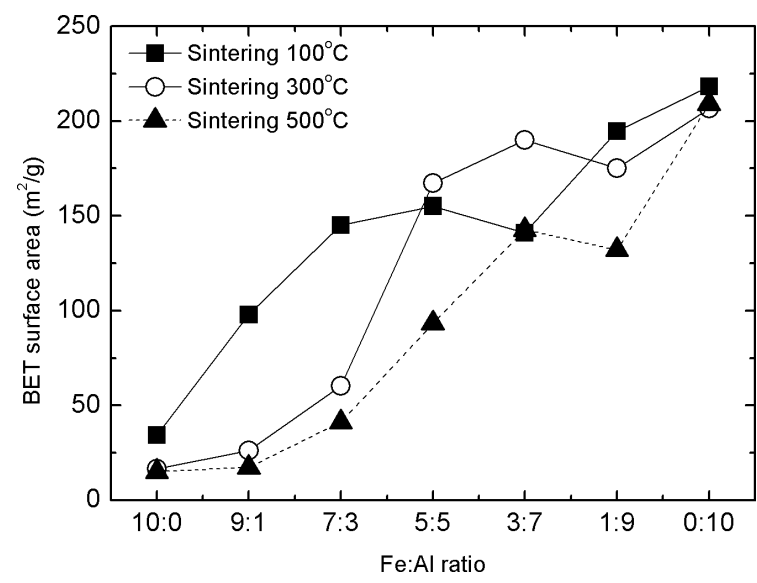

Fig. 3 BET surface area of $\mathrm{Fe}-\mathrm{Al}$ oxide according to $\mathrm{Fe}: \mathrm{Al}$ ratio and sintering temperature.

The BET surface area of Fe-Al binary oxide is increased in proportion to the incorporated amount of $\mathrm{Al}$ at all sintering temperatures. This tendency is more clearly observed at a sintering temperature of $500^{\circ} \mathrm{C}$. Compared with Al-oxide, the $\mathrm{Fe}$-oxide surface is almost negligible in the $500^{\circ} \mathrm{C}$ sintered case. The surface area shows a linear slope with the incorporated amount of $\mathrm{Al}$. In a series of BET experiments, we conclude that $\mathrm{Al}$ in Fe-oxide expands the surface area in the mixture, which is a crucial factor for pollutant adsorption.

\subsection{Crystalline phase of Fe-Al binary oxides}

Figure 4 shows the XRD patterns of Fe-Al binary oxide for various $\mathrm{Fe}: \mathrm{Al}$ ratios and sintering temperatures. Pure Fe-oxide $(\mathrm{Fe}: \mathrm{Al}$ ratio = 10:0) shows a phase transition depending on sintering temperature. Fe-oxide sintered at $100^{\circ} \mathrm{C}$ shows an almost amorphous structure. The broad (111) peak indicates a slightly crystalline $\alpha$-FeOOH phase. When the sintering temperature increases above $300^{\circ} \mathrm{C}$, the XRD pattern is clearly changed. The (111) peak disappears, and a sharp $\alpha$ - $\mathrm{Fe}_{2} \mathrm{O}_{3}$ (hematite) peak is observed. Increasing temperature leads to a dehydroxylation reaction accompanied by transformation from $\mathrm{Fe}$-oxyhydroxide to $\alpha-\mathrm{Fe}_{2} \mathrm{O}_{3}$, as described ${ }^{17}$ )

$$
2 \mathrm{FeOOH} \rightarrow \alpha-\mathrm{Fe}_{2} \mathrm{O}_{3}+\mathrm{H}_{2} \mathrm{O}
$$

However, $\mathrm{Fe}_{3} \mathrm{O}_{4}$ is also mixed with $\alpha-\mathrm{Fe}_{2} \mathrm{O}_{3}$ due to insufficient oxygen in the furnace. The (220), (400) and (551) peaks are evidence of a co-existing $\mathrm{Fe}_{3} \mathrm{O}_{4}$ (magnetite) phase ${ }^{18)}$. The incorporation of $\mathrm{Al}$ into $\mathrm{Fe}$-oxide affects the phase transition of Fe-oxide depending on sintering temperature.

The oxides with $\mathrm{Fe}: \mathrm{Al}$ ratios of $9: 1$ and 7:3 sintered at above $300^{\circ} \mathrm{C}$ show broader $\alpha-\mathrm{Fe}_{2} \mathrm{O}_{3}$ peaks compared to pure $\mathrm{Fe}$-oxide. In addition, the $\mathrm{Fe}_{3} \mathrm{O}_{4}$ peak intensity is significantly increased, which indicates that the incorporation of $\mathrm{Al}$ into Fe-oxide consumes oxygen during thermal treatment and inhibits the phase transition of $\mathrm{Fe}$-oxide. The intermediate phase $\left(\mathrm{Fe}_{3} \mathrm{O}_{4}\right)$ is increased at the same thermal condition $\left(300^{\circ} \mathrm{C}\right)$.

For the binary oxide with the Fe:Al ratio of 5:5, the effects of $\mathrm{Al}$ incorporation into $\mathrm{Fe}$-oxide are more obvious. In the $300^{\circ} \mathrm{C}$ sintered $\mathrm{Fe}-\mathrm{Al}$ binary oxide, $\alpha$-FeOOH and $\mathrm{Fe}_{3} \mathrm{O}_{4}$ peaks are observed instead of $\alpha-\mathrm{Fe}_{2} \mathrm{O}_{3}$ peaks, indicating that the phase transition of $\mathrm{Fe}$-oxide does not occur for a $\mathrm{Fe}: \mathrm{Al}$ 

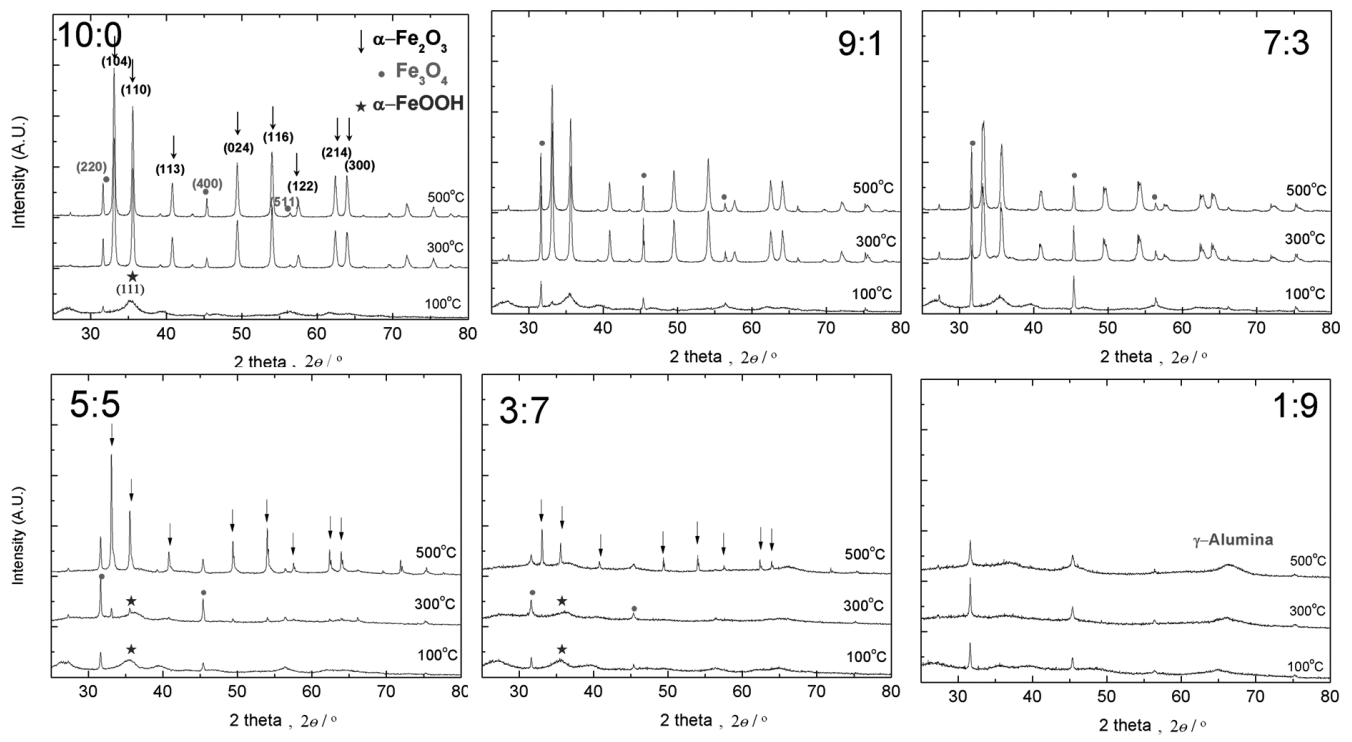

Fig. 4 XRD analysis of Fe-Al binary oxide according to various Fe:Al ratio and sintering temperature.

ratio of 5:5 at $300^{\circ} \mathrm{C}$. In pure Fe-oxide, a highly crystalline $\alpha-\mathrm{Fe}_{2} \mathrm{O}_{3}$ phase is obtained at the same temperature, which means that the incorporation of $\mathrm{Al}$ into Fe-oxide completely interfered with the thermal phase transition of Fe-oxide. At a higher sintering temperature of $500^{\circ} \mathrm{C}, \alpha-\mathrm{Fe}_{2} \mathrm{O}_{3}$ peaks finally appear. It is clear that the phase transition temperature moves to a higher value due to incorporating $\mathrm{Al}$. Based on the XRD results, the incorporation of $\mathrm{Al}$ inhibited the structure conversion of Fe-oxide caused by the thermal treatment, elevating the phase conversion temperature ${ }^{19)}$. In the case of pure Fe-oxide, the phase transition from $\alpha$ - $\mathrm{FeOOH}$ to $\alpha-\mathrm{Fe}_{2} \mathrm{O}_{3}$ occurs below $300^{\circ} \mathrm{C}$, while the same phase transition occurs above $300 \sim 500^{\circ} \mathrm{C}$ when $\mathrm{Al}$ is incorporated into $\mathrm{Fe}$-oxide. This XRD result, that the phase transition shifts to a higher temperature with increasing $\mathrm{Al}$ content, is consistent with the SEM results (Fig. 2) showing minimal morphological change of binary mixtures incorporating $\mathrm{Al}$ at elevated sintering temperatures.

Meanwhile, almost no phase conversion is observed for the $\mathrm{Fe}-\mathrm{Al}$ binary oxide with the $\mathrm{Fe}: \mathrm{Al}$ ratio of 9:1. Because the amount of $\mathrm{Fe}$-oxide is only $10 \%$, the XRD patterns that indicate Fe-oxide are almost absent. At $500^{\circ} \mathrm{C}$, a poorly crystallized $\gamma-\mathrm{Al}_{2} \mathrm{O}_{3}$ peak appears.

\subsection{Heavy metal adsorption performance of $\mathrm{Fe}-\mathrm{Al}$ bina- ry oxides}

The heavy metal adsorption capacities of prepared Fe-Al binary oxides were evaluated. $\mathrm{As}(\mathrm{V})$ and $\mathrm{Se}(\mathrm{VI})$ were selected as model heavy metal ions. Figure 5 shows the As(V) and $\mathrm{Se}(\mathrm{VI})$ uptake on synthesized Fe-Al binary oxides with various Fe:Al ratios. As(V) and $\mathrm{Se}(\mathrm{VI})$ show similar adsorption behavior. Regardless of Fe:Al ratio, Fe-Al binary oxide sintered at $100^{\circ} \mathrm{C}$ showed the highest heavy metal uptake. The oxides sintered at $100^{\circ} \mathrm{C}$ consist of oxy-hydroxide phase metal oxide $(\mathrm{FeOOH}$ and amorphous $\mathrm{AlO}(\mathrm{OH}))$. The many hydroxyl groups on oxy-hydroxide phase metal oxide can effectively chelate heavy metal ions. Several reports have noted that oxyhydroxide is more effective for the adsorption of heavy metals than an oxide structure ${ }^{5,20)}$.
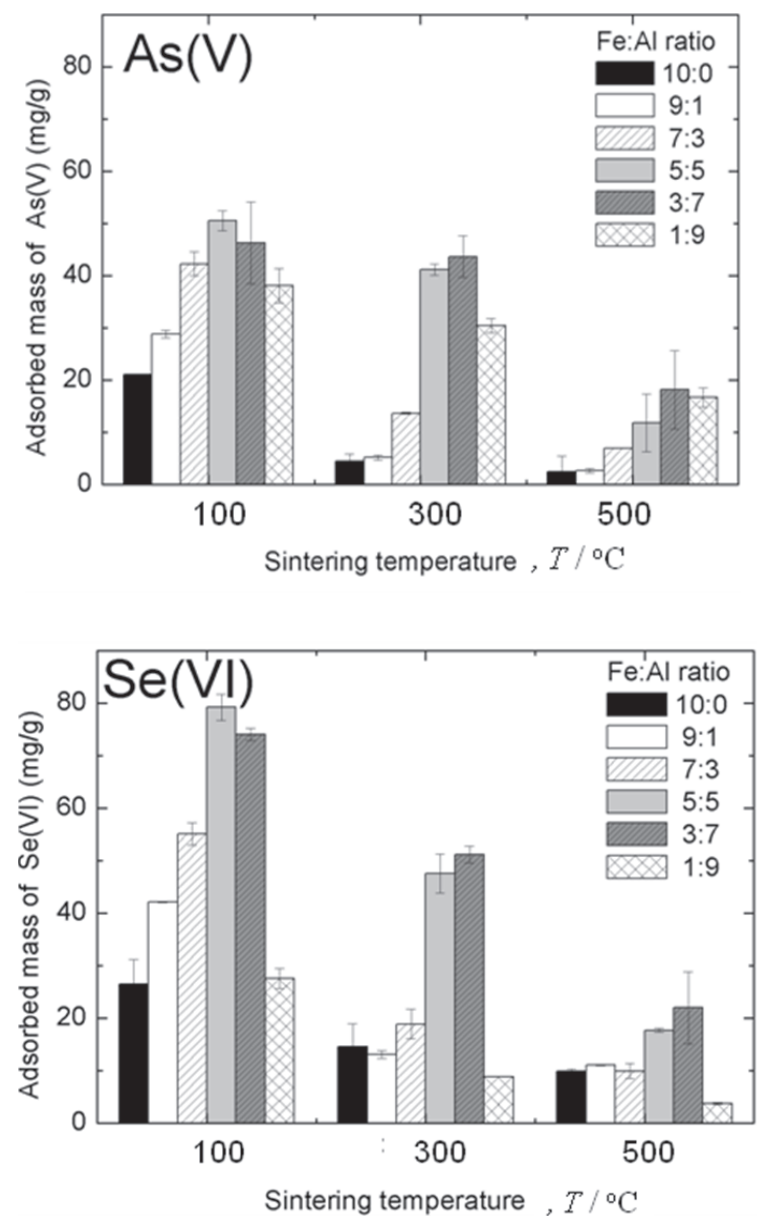

Fig. $5 \mathrm{As}(\mathrm{V})$ and $\mathrm{Se}(\mathrm{VI})$ uptake of $\mathrm{Fe}-\mathrm{Al}$ binary oxide according to $\mathrm{Fe}: \mathrm{Al}$ ratio and sintering temperature.

Among the samples sintered at $100^{\circ} \mathrm{C}$, the highest $\mathrm{As}(\mathrm{V})$ and $\mathrm{Se}(\mathrm{VI})$ uptake was obtained with the Fe:Al ratio of 5:5, which is attributed to the expansion of the surface area with increasing $\mathrm{Al}$ content in the Fe-Al binary oxide. The increased surface area promotes heavy metal contact with the Fe-oxide, 
but the decreasing amount of Fe-oxide does not, indicating an optimum Fe:Al ratio for heavy metal removal. In this study, the optimum $\mathrm{As}(\mathrm{V})$ and $\mathrm{Se}(\mathrm{VI})$ uptake was obtained with the $\mathrm{Fe}: \mathrm{Al}$ ratio of 5:5. Further increases in $\mathrm{Al}$ content (Fe:Al ratios 3:7 and 1:9) caused a lack of Fe-oxide adsorption sites for $\mathrm{As}(\mathrm{V})$ and $\mathrm{Se}(\mathrm{VI})$.

Not only Fe-Al binary oxides sintered at $100^{\circ} \mathrm{C}$ but also the oxides sintered at high temperature $\left(300 \sim 500^{\circ} \mathrm{C}\right)$ showed increased $\mathrm{As}(\mathrm{V})$ and $\mathrm{Se}(\mathrm{VI})$ uptake in proportion to $\mathrm{Al}$ content until the critical $\mathrm{Fe}: \mathrm{Al}$ ratio. For the oxides sintered at $300^{\circ} \mathrm{C}$ and $500^{\circ} \mathrm{C}$, the $\mathrm{Fe}: \mathrm{Al}$ ratio of 3:7 showed the best $\mathrm{As}(\mathrm{V})$ and $\mathrm{Se}$ (VI) uptake instead of the 5:5 ratio, which is attributed to the effect of $\mathrm{Al}$ content on the phase transition of the $\mathrm{Fe}-\mathrm{Al}$ oxide. At a $300^{\circ} \mathrm{C}$ sintering temperature, the pure $\mathrm{Fe}$-oxide phase $(\alpha-\mathrm{FeOOH})$ transitions to $\alpha-\mathrm{Fe}_{2} \mathrm{O}_{3}$ or $\mathrm{Fe}_{3} \mathrm{O}_{4}$, which is less effective for heavy metal adsorption. Our SEM and XRD results show that the incorporation of $\mathrm{Al}$ delays the phase transition of $\mathrm{Fe}$-oxide above $300^{\circ} \mathrm{C}$. In other words, the more $\mathrm{Al}$ is incorporated into the $\mathrm{Fe}-\mathrm{Al}$ binary oxide, the more of the $\alpha$-FeOOH phase remains in the Fe-Al binary oxide. Thus, in contrast to the $\mathrm{Fe}-\mathrm{Al}$ binary oxides sintered at $100^{\circ} \mathrm{C}$, a $3: 7$ $\mathrm{Fe}: \mathrm{Al}$ ratio, which incorporates more $\mathrm{Al}$, shows the highest $\mathrm{As}(\mathrm{V})$ and $\mathrm{Se}(\mathrm{VI})$ uptake.

In conclusion, the incorporation of $\mathrm{Al}$ expands the surface area of Fe-oxide and also affects the phase transition temperature and crystallinity of Fe-oxide. Thus, the incorporation of an appropriate amount of Al controls the surface area and effective Fe-oxide phase, which are closely related to heavy metal removal. For example, the Fe-Al binary oxide with a 5:5 Fe:Al ratio sintered at $100^{\circ} \mathrm{C}$ exhibits $50.5 \mathrm{mg} / \mathrm{g}$ and $79.2 \mathrm{mg} / \mathrm{g}$ of $\mathrm{As}(\mathrm{V})$ and $\mathrm{Se}(\mathrm{VI})$ uptake, respectively, which are 2.5 times and 3 times higher uptake than pure Fe-oxide. It is thus demonstrated that the heavy metal adsorption performance of Fe-oxide is significantly improved by the incorporation of $\mathrm{Al}$.

\section{Conclusion}

In this study, we describe a method to improve the heavy metal adsorption capacity of Fe-oxide by incorporating $\mathrm{Al}$, and discuss the characteristic changes and ultimate influence on arsenate $(\mathrm{As}(\mathrm{V}))$ and selenate $(\mathrm{Se}(\mathrm{VI}))$ removal. Fe-Al binary oxides with various Fe:Al ratios (10:0, 9:1, 7:3, 5:5, 3:7 and 1:9) are synthesized by the sol-gel method followed by a sintering process. SEM with EDS analysis reveals that Fe and $\mathrm{Al}$ are homogeneously mixed without phase separation. The surface area of the Fe-Al binary oxide increases proportionally with the $\mathrm{Al}$ content. The oxide with a $\mathrm{Fe}: \mathrm{Al}$ ratio of 5:5 shows a $90 \sim 150 \mathrm{~m}^{2} / \mathrm{g}$ surface area, which is more than 10 times the surface area of pure Fe-oxide. Sintering above $300^{\circ} \mathrm{C}$ causes deformation of the Fe-oxide due to coarsening and a phase transformation from $\alpha-\mathrm{FeOOH}$ to $\alpha-\mathrm{Fe}_{2} \mathrm{O}_{3}$. The incorporation of $\mathrm{Al}$ into $\mathrm{Fe}$-oxide inhibits both the surface deformation and phase transition.
Among various Fe:Al ratio binary oxides, the highest $\mathrm{As}(\mathrm{V})$ and $\mathrm{Se}(\mathrm{VI})$ uptake was obtained with a 5:5 Fe:Al ratio oxide sintered at $100^{\circ} \mathrm{C}$ due to the expanded surface area and increased $\alpha$-FeOOH phase, which provides a sufficient amount of hydroxyl groups. Further increases in Al content resulted in decreased $\mathrm{As}(\mathrm{V})$ and $\mathrm{Se}(\mathrm{VI})$ removal due to the lack of Fe-oxide.

In $\mathrm{Fe}-\mathrm{Al}$ binary oxide sintered at 300 and $500^{\circ} \mathrm{C}$, the phase transition of $\mathrm{Fe}$-oxide occurs and $\mathrm{As}(\mathrm{V})$ and $\mathrm{Se}(\mathrm{VI})$ uptake is decreased compared with oxides sintered at $100^{\circ} \mathrm{C}$. A Fe:Al ratio of 3:7 shows the best $\mathrm{As}(\mathrm{V})$ and $\mathrm{Se}(\mathrm{VI})$ uptake because of the maintenance of the $\alpha$-FeOOH phase by the incorporation of Al.

\section{Acknowledgments}

This research was supported in part by the Basic Research Project (GP2015-019, 16-3220) of the Korea Institute of Geoscience and Mineral Resources (KIGAM), Korea Institute of Science and Technology (KIST) Institutional Program (No. 2Z04720) and Nano-Material Technology Development Program through the National Research Foundation of Korea (2016M3A7B4905619).

\section{REFERENCES}

1) U.S.R.M. Cornell, The iron oxides. Structure, properties, reactions occurrences and uses., Wiley-VCH, 2000.

2) J.-C. Hsu, C.-J. Lin, C.-H. Liao and S.-T. Chen: J. Hazard. Mater. 153 (2008) 817-826.

3) S. Kuo and R. Bembenek: Bioresour. Technol. 99 (2008) 5617-5625.

4) J. Gimenez, M. Martinez, J. de Pablo, M. Rovira and L. Duro: J. Hazard. Mater. 141 (2007) 575-580.

5) R.J. Bowell: Appl. Geochem. 9 (1994) 279-286.

6) D. Peak and D.L. Sparks: Environ. Sci. Technol. 36 (2002) 1460-1466.

7) Y.-H. Huang, C.-L. Hsueh, H.-P. Cheng, L.-C. Su and C.-Y. Chen: J. Hazard. Mater. 144 (2007) 406-411.

8) M. Rovira, J. Giménez, M. Martínez, X. Martínez-Lladó, J. de Pablo, V. Martí and L. Duro: J. Hazard. Mater. 150 (2008) 279-284.

9) L.S. Zhong, J.S. Hu, H.P. Liang, A.M. Cao, W.G. Song and L.J. Wan: Adv. Mater. 18 (2006) 2426-2431.

10) L. Wei, G. Yang, R. Wang and W. Ma: J. Hazard. Mater. 164 (2009) 1159-1163.

11) K. Gupta and U.C. Ghosh: J. Hazard. Mater. 161 (2009) 884-892.

12) G. Zhang, J. Qu, H. Liu, R. Liu and R. Wu: Water Res. 41 (2007) 19211928.

13) G.-S. Zhang, J.-H. Qu, H.-J. Liu, R.-P. Liu and G.-T. Li: Environ. Sci. Technol. 41 (2007) 4613-4619.

14) P. Suresh Kumar, R.Q. Flores, C. Sjöstedt and L. Önnby: J. Hazard. Mater. 302 (2016) 166-174.

15) H.-J. Hong, W. Farooq, J.-S. Yang and J.-W. Yang: Sep. Sci. Technol. 45 (2010) 1975-1981.

16) Y.-H. Huang, Y.-J. Shih and C.-C. Chang: J. Hazard. Mater. 186 (2011) 1355-1359.

17) R. Derie, M. Ghodsi and C. Calvo-Roche: J. Therm. Anal. 9 435-440.

18) X. Zhang, Y. Niu, X. Meng, Y. Li and J. Zhao: CrystEngComm 15 (2013) 8166-8172.

19) Y. K. F. Gulshan, A. Nakajima, K. Okada, Proc. Waste Eng., 2008, 237-242.

20) M.G. Sujana and S. Anand: Appl. Surf. Sci. 256 (2010) 6956-6962. 